\title{
Design your strategy, define your costs: third or subsequent-lines in advanced gastrointestinal stromal tumors (GIST)
}

\author{
Jacopo Giuliani^ \\ Department of Oncology, Mater Salutis Hospital, Az. ULSS 9 Scaligera, Legnago (VR), Italy \\ Correspondence to: Jacopo Giuliani, Department of Oncology, Az. ULSS 9 Scaligera, Via Gianella 1-37045, Legnago (VR), Italy. \\ Email: giuliani.jacopo@alice.it.
}

Received: 03 March 2021; Accepted: 30 July 2021; Published: 06 August 2021.

doi: 10.21037 /gist-21-5

View this article at: https://dx.doi.org/10.21037/gist-21-5

The topic of costs has become one of the main topics in oncology, as well as in relation to the introduction on target biological agents, with their greatest budgetary impact (1). The treatment of advanced/metastatic gastrointestinal stromal tumors (GIST) has radically changed with the introduction of imatinib (2) in first-line treatment in 2002 (3). In case of progression of the disease (after dose increase of imatinib from 400 to $800 \mathrm{mg} /$ daily), other tyrosine kinase inhibitors (TKIs) are indicated in subsequent lines, with the introduction of sunitinib first in 2006 (4) and regorafenib after in 2013 (5). These indications (sunitinib and regorafenib after imatinib) raises the main problem of pharmacy costs increase. The aim of this paper was to assess the cost-effectiveness of sunitinib and regorafenib in advanced GIST patients in subsequent lines after progression from imatinib.

Pivotal phase III randomized controlled trials (RCTs) were considered $(4,5)$. Incremental cost-effectiveness ratio (ICER) was calculated as the ratio between the difference of the costs in the intervention and in the control groups (pharmacy costs) and the difference between the effect in the intervention and in the control groups [progression-free survival (PFS)]. The costs of drugs are at the Mater Salutis Hospital of Legnago (VR, Italy) and are expressed in euros (€) (prices sourced as of December 2020). We assumed the following costs: sunitinib $=163.59 €$ for $50 \mathrm{mg}$ tablet (one tablet per day for 28 consecutive days every 42 days), regorafenib $=21.89 €$ for $40 \mathrm{mg}$ tablet (4 tablets per day for 21 consecutive days every 28 days). The costs used are already consider the confidential rebates.

Five hundred eleven patients were included $(4,5)$. European Society for Medical Oncology-Magnitude of Clinical Benefit Scale (ESMO-MCBS) reached grade 4 for both RCTs. Sunitinib resulted with a cost of $954.28 €$ per month of PFS-gain and regorafenib with a cost of $2,828.86 €$ per month of PFS-gain (Table 1).

The efficacy of treatment in the first strong variable that could be condition pharmacological costs and efficacy is determined by RCTs results (that are related to the patient's inclusion criteria). This is also the main limit: results from RTCs could be not representative of daily clinical practice (6). The price of drugs is the second strong variable and it is related to the difference in pharmacy costs within different European countries (in Italy there are no significant pharmacy cost differences between the different regional realities), due to the use of local pharmacy cost (referring to external reference pricing). In this specific case, the costs standardization bias is minimized by the comparison with placebo. Another limit is related to the consideration of only the costs of drugs (which account for about $55 \%$ of total medical expenses). The cross-trial comparison is an additional limit.

In Europe expenditure for cancer drugs amounted to $€ 10$ billion in the year 2005 and increased more than three times to $€ 32$ billion in the year 2018 (7). This situation could introduce a new type of resistance, not linked to biological mechanism, but to the increase of costs of novel treatments, that we can call "costs resistance". In several Countries this

$\wedge$ ORCID: 0000-0003-4096-2514. 


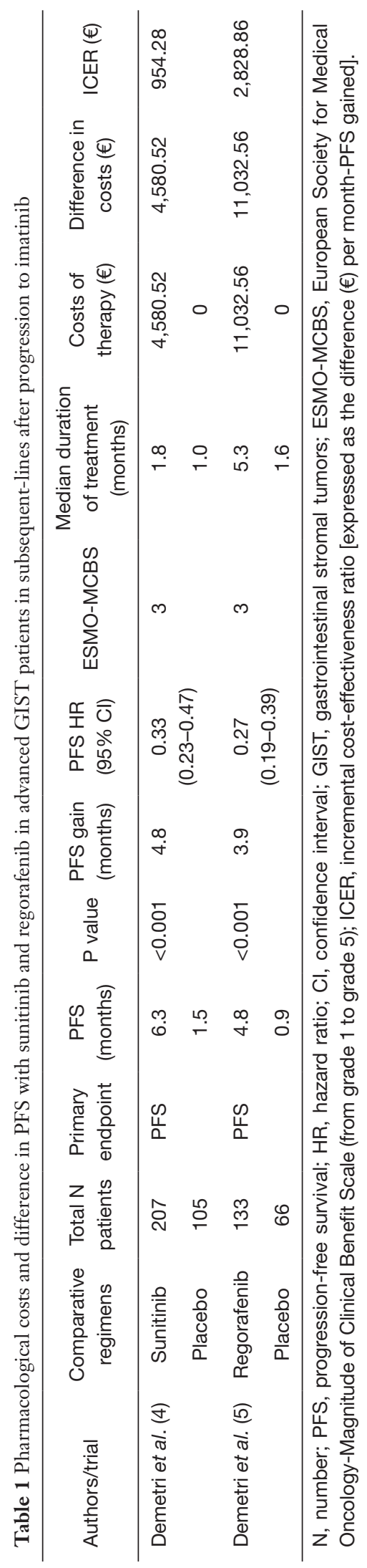

could results in precluding new oncological treatments.

To our knowledge, this is the first time an analysis of the pharmacological costs of sunitinib and regorafenib in advanced GIST patients in subsequent-lines after progression to imatinib is linked to PFS.

In addition, the annual perspective to get 12 months of PFS with both sunitinib $(11,451.36 €)$ and regorafenib $(33,939.12 €)$ in this setting are in line with those reported in literature $(57,138 €)(8)$. To this we must add that the margin to define an effective treatment $(45,686.64 €$ for sunitinib and 23,198.88 € for regorafenib) is quite high and difficult to overcame even in presence of significative differences in pharmacy costs between the different countries.

In conclusion, combining pharmacological costs of drugs with the measure of efficacy represented by PFS, both sunitinib and regorafenib could be considered cost-effective treatments in advanced GIST patients in subsequent lines after progression to imatinib.

\section{Acknowledgments}

Funding: None.

\section{Footnote}

Provenance and Peer Review: This article was commissioned by the Editorial Office, Gastrointestinal Stromal Tumor. The article has undergone external peer review.

Conflicts of Interest: The author has completed the ICMJE uniform disclosure form (available at https://dx.doi. org/10.21037/gist-21-5). JG serves as the unpaid editorial board member of Gastrointestinal Stromal Tumor from Dec 2020 to Nov 2022. The author has no other conflicts of interest to declare.

Ethical Statement: The author is accountable for all aspects of the work in ensuring that questions related to the accuracy or integrity of any part of the work are appropriately investigated and resolved.

Open Access Statement: This is an Open Access article distributed in accordance with the Creative Commons Attribution-NonCommercial-NoDerivs 4.0 International License (CC BY-NC-ND 4.0), which permits the noncommercial replication and distribution of the article with the strict proviso that no changes or edits are made and the 
original work is properly cited (including links to both the formal publication through the relevant DOI and the license). See: https://creativecommons.org/licenses/by-nc-nd/4.0/.

\section{References}

1. Giuliani J, Bonetti A. The Economic Impact of Biosimilars in Oncology and Hematology: The Case of Trastuzumab and Rituximab. Anticancer Res 2019;39:3971-3.

2. Reichardt P. The Story of Imatinib in GIST - a Journey through the Development of a Targeted Therapy. Oncol Res Treat 2018;41:472-7.

3. Demetri GD, von Mehren M, Blanke CD, et al. Efficacy and safety of imatinib mesylate in advanced gastrointestinal stromal tumors. N Engl J Med 2002;347:472-80.

4. Demetri GD, van Oosterom AT, Garrett CR, et al.

doi: $10.21037 /$ gist-21-5

Cite this article as: Giuliani J. Design your strategy, define your costs: third or subsequent-lines in advanced gastrointestinal stromal tumors (GIST). Gastrointest Stromal Tumor 2021;4:3.
Efficacy and safety of sunitinib in patients with advanced gastrointestinal stromal tumour after failure of imatinib: a randomised controlled trial. Lancet 2006;368:1329-38.

5. Demetri GD, Reichardt P, Kang YK, et al. Efficacy and safety of regorafenib for advanced gastrointestinal stromal tumours after failure of imatinib and sunitinib (GRID): an international, multicentre, randomised, placebocontrolled, phase 3 trial. Lancet 2013;381:295-302.

6. Malmivaara A. Generalizability of findings from randomized controlled trials is limited in the leading general medical journals. J Clin Epidemiol 2019;107:36-41.

7. Hofmarcher T, Lindgren P, Wilking N, et al. The cost of cancer in Europe 2018. Eur J Cancer 2020;129:41-9.

8. Azimi NA, Welch HG. The effectiveness of costeffectiveness analysis in containing costs. J Gen Intern Med 1998;13:664-9. 